\title{
Endovascular repair of arterio-bronchial fistula of the outflow graft of HeartMate II left ventricular assist device
}

\author{
Roh Yanagida, MD, PhD, ${ }^{\mathrm{a}}$ Robert Kass, MD, ${ }^{\mathrm{a}}$ Lawrence Czer, MD, ${ }^{\mathrm{b}}$ and Ali Khoynezhad, MD, ${ }^{\mathrm{a}}$ \\ Los Angeles, Calif
}

Arterio-bronchial fistula in combination with prosthetic vascular graft infection is a formidable challenge for surgeons. We describe a patient with arterio-bronchial fistula of the outflow graft of a left ventricular assist device (LVAD) who presented with hemoptysis and hemothorax.

\section{CLINICAL SUMMARY}

The patient is a 58 -year-old obese female who underwent implantation of a HeartMate XVE (Thoratec Corp, Pleasanton, Calif) for advanced heart failure. The LVAD was exchanged for a HeartMate II (Thoratec Corp) within 15 months because of device failure. Four months later, she presented with copious hemoptysis. She was hemodynamically stable with a patent airway. Computed tomography (CT) angiogram of the chest revealed a right hemothorax and extravasation of the contrast at the midportion of the outflow graft of the LVAD (Figure 1). This location corresponded to the site of the Dacron graft to graft anastomosis or the de-airing site. Emergency surgical exploration and graft repair were contemplated; however, morbidity of a third sternotomy was considered significant in this anticoagulated, obese patient. Furthermore, the right hemothorax was considered contaminated with lower respiratory bacterial flora, which can cause a deep sternal wound infection; therefore, we decided to proceed with a non-sternotomy option, such as an endovascular approach.

In a hybrid operating room, a pigtail catheter was advanced through the left femoral artery into the outflow graft that was anastomosed to the mid-ascending aorta. Preprocedural angiogram confirmed active extravasation of the contrast. The right common carotid artery was chosen for stent graft delivery. After the right common carotid artery was exposed, the patient was heparinized. Via a $5 \mathrm{~F}$ sheath, an $180-\mathrm{cm}$ Nitrex wire was advanced into the ascending aorta

$\overline{\text { From the Divisions of Cardiothoracic Surgery }}{ }^{\mathrm{a}}$ and Cardiology, ${ }^{\mathrm{b}}$ Cedars-Sinai Heart Institute, Los Angeles, Calif.

Disclosures: Authors have nothing to disclose with regard to commercial support.

Received for publication Oct 4, 2010; accepted for publication Nov 15, 2010; available ahead of print Jan 27, 2011.

Address for reprints: Roh Yanagida, MD, PhD, 8700 Beverly Blvd, North Tower

Room 6215, Los Angeles, CA 90048 (E-mail: roh.yanagida@cshs.org).

J Thorac Cardiovasc Surg 2011;142:710-1

0022-5223/ $\$ 36.00$

Copyright (C) 2011 by The American Association for Thoracic Surgery

doi: $10.1016 /$ j.jtcvs.2010.11.021

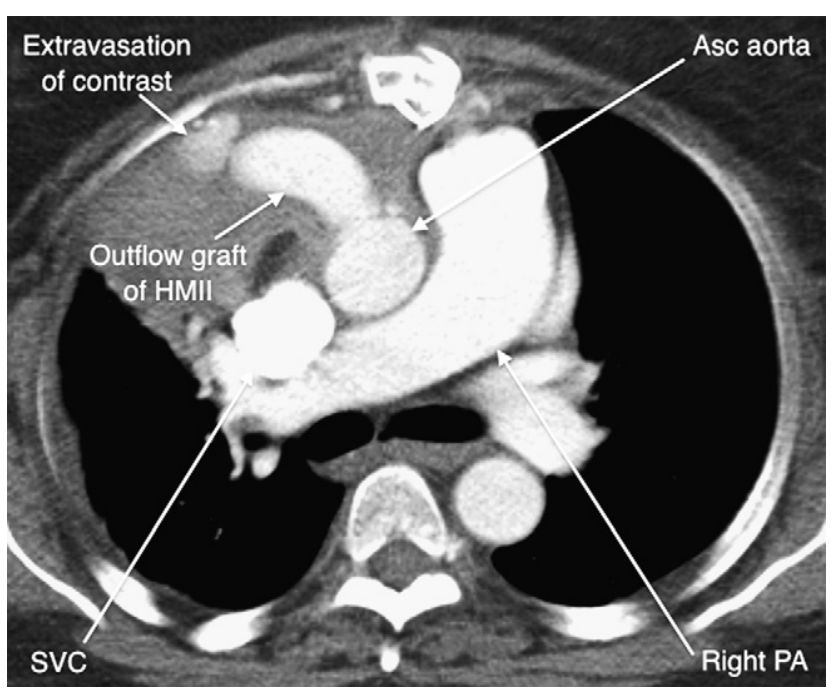

FIGURE 1. Computed tomography scan shows extravasation of contrast at the mid-portion of the outflow graft of the left ventricular assist device. Asc, Ascending; PA, pulmonary artery; HMII, HeartMate II; SVC, superior vena cava.

and subsequently into the outflow graft. The wire was carefully "parked" just downstream from the rotor inside the LVAD. The outflow graft was $16 \mathrm{~mm}$, measured on the basis of the CT findings and intraoperative angiogram. A $20 \times 55$ mm AneuRx iliac limb stent graft (Medtronic, Santa Rosa, Calif) was deployed in the outflow graft. Completion angiogram showed a type Ib endoleak; therefore, a second AneuRx aortic cuff stent graft $(22 \times 40 \mathrm{~mm})$ was placed just distal to the first graft flush to the ascending aorta. A repeat angiogram revealed successful endovascular repair (Figure 2).

On postoperative day 1 , neurologic examination revealed slight motor weakness in the left foot; however, the patient regained full strength 2 days later and was discharged on postoperative day 6 with long-term antibiotics. A follow-up CT scan before her discharge revealed a successful endovascular exclusion of the arterio-bronchial fistula.

\section{DISCUSSION}

Arterio-bronchial fistula with involvement of a prosthetic vascular graft is a significant surgical challenge that usually requires excision of the graft with extra-anatomic bypass. 


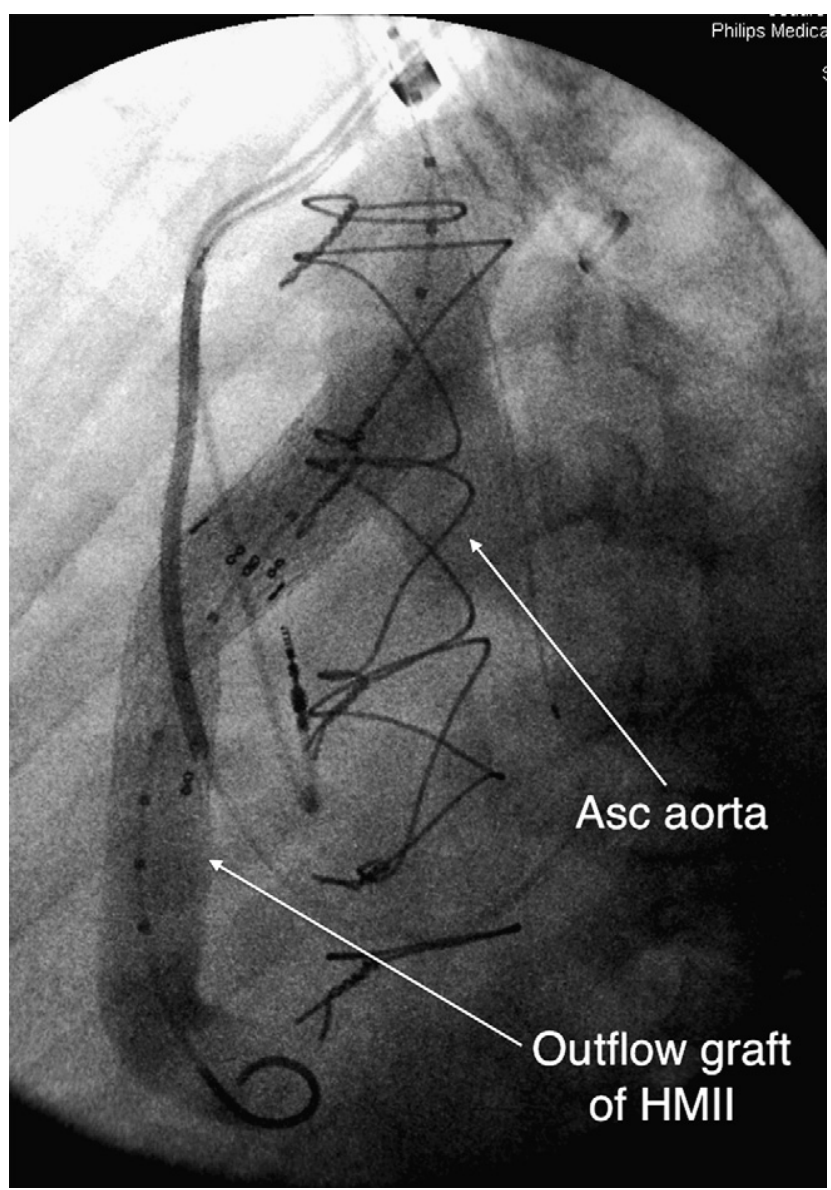

FIGURE 2. Completion angiogram shows successful endovascular repair of the arterio-bronchial fistula. Asc, Ascending; HMII, HeartMate II.

Endovascular stenting for aorto-bronchial fistula has been reported ${ }^{1-3}$ and although long-term follow-up is missing, early success rates are encouraging. ${ }^{4}$ Infection of the deployed stent graft is of significant concern and needs to be part of the informed consent.

Although endovascular stenting was expected to be less morbid than re-sternotomy, this procedure was risky because of the following technical aspects. First, there was the concern whether the stiff guidewire could be advanced enough to achieve adequate "purchase" for stent graft trackability and deployment. Second, close attention was required to the distal end of the wire to prevent its impingement on the LVAD rotor, understanding that a small advancement of the wire could cause rotor malfunction resulting in possible hemodynamic collapse in this patient. Third, given the size of the Dacron graft, an off-label abdominal stent graft had to be used. The abdominal stent grafts have a shorter delivery system; therefore, an upper body arterial delivery was mandatory. The left axillary artery approach was not possible because of the implanted cardioverter defibrillator in the region of the left subclavian artery, and the right subclavian artery was impractical because of tortuosity; therefore, the right carotid artery was the only option for this patient.

To our knowledge, an endovascular repair within an LVAD has not been reported in the literature. The longterm outcome of a stent graft within an LVAD outflow graft is unknown. This is especially true in the setting of a presumed contaminated field. Long-term antibiotics will be administered to the patient, and she will be followed closely with CT and clinical examination per endovascular protocol.

\section{CONCLUSIONS}

A hemoptysizing patient with arterio-bronchial fistula of the outflow graft of LVAD underwent successful endovascular exclusion via the right common carotid artery. The endovascular approach is an attractive alternative in a patient with prohibitive risk for an open surgical approach.

\section{References}

1. Yoo JH, Lee CT, Shim YS, Chung JW, Ahn H, Kim KW. Aortobronchial fistula presenting as recurrent hemoptysis and successfully treated with an endovascular stent graft. Respiration. 2001;68:537-9.

2. Smayra T, Otal P, Soula P, Chabbert V, Cérène A, Joffre F, et al. Pseudoaneurysm and aortobronchial fistula after surgical bypass for aortic coarctation: management with endovascular stent-graft. J Endovasc Ther. 2001;8:422-8.

3. Davison BD, Ring DH, Bueno R, Jaklitsch MT. Endovascular stent-graft repair of a pulmonary artery-bronchial fistula. J Vasc Interv Radiol. 2003;14: 929-32.

4. Wheatley GH 3rd, Nunez A, Preventza O, Ramaiah VG, Rodriguez-Lopez JA, Williams J, et al. Have we gone too far? Endovascular stent-graft repair of aortobronchial fistulas. J Thorac Cardiovasc Surg. 2007;133:1277-85. 